\title{
Developing And Implementing Faculty Performance Evaluation: A Collaborative Model
}

Robert W. Caldwell Jr., (Email:_caldwell@universe.uiwtx.edu), University of the Incarnate Word Michael Schulte, (Email: mschulte@ concentric.net), University of the Incarnate Word

\begin{abstract}
The quality of education is a core property of what makes a university operate, sustain, and grow. To evaluate and measure this core property encompasses a wide range of critical aspects, but one of the control mechanisms will always involve the faculty, the deliverers of education to the primary customer, the student, but also collaboratively to other faculty, other educators, staff, and the community itself. Faculty, like students constantly change, the challenge being how to inculcate a viable system of performance evaluation that provides a consistently high quality education in the ever changing and information oriented world we live in. This paper illustrates the process, and problems we've experienced and solutions we have used in implementing a new faculty performance evaluation system at our university. We describe the development of the system; its components, the intended outcomes, issues and resistance encountered as the system was implemented and now, how we envision the growth of the system, and what it needs to remain viable and in tune with our overall strategic plan.
\end{abstract}

\section{Introduction and Purpose}

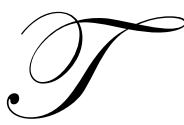

he purpose of this paper is to describe how a small, but consistently ranked college in the southwest by US News and World Report (Available at URL: http://www.usnews.com) developed a comprehensive faculty evaluation system in response to needs expressed by the faculty and administration. Emphasis throughout this paper will be focused on the innovative and imaginative collaboration between individual faculty members and key administration officials to implement and expand upon fundamental personnel management, strategic planning, and organizational behavior concepts, more fully integrating them into the overall strategic plan of the university.

Appraising the performance of employees has long been recognized as an important method for achieving excellence in businesses. The appraisals provide the basis for key decisions regarding compensation, promotion, and employee development, as well as measuring progress toward achieving organizational and individual employee goals. When an effective performance evaluation system is absent, organizations experience a wide range of problems, not the least of which is employee dissatisfaction and lowered productivity. It is interesting to note that in academia, instructors tend to resist appraisal of their performance, while at the same time, applying those same concepts to their students (Bright \& Richards, 2001). As stated previously, this paper describes the circumstances leading to the development of a comprehensive performance appraisal system in a university and is intended to provide a model for the collaborative activity between faculty and administration to improve organizational effectiveness.

\section{The University of the Incarnate Word - Background and Today}

In order to understand the environment for this activity, the following background is provided. The University of the Incarnate Word in San Antonio, Texas has its roots in service dating back to the end of the Civil War.

Readers with comments or questions are encouraged to contact the authors via email. 
Started by three young nuns from France, the college began with nursing and education programs. It has grown to University status and currently has an enrollment of approximately 4300 students, and grants Bachelors, Masters, and Doctoral degrees. Educational programs include Nursing, Education, Business Administration, Science and Engineering and traditional Liberal Arts. There is also an on-line program (Virtual University) and an Adult Completion Program (AdCap). The University consists of five Colleges with a full time faculty of 121 persons. Additionally, there are campuses through out Texas and a new joint venture with China which is expected to have 150 students in 2002.

University Administration consists of the President, Chancellor, Provost and Vice Presidents for the various functional areas including Academic Affairs. Faculty governance consists of the Faculty Senate and the traditional committees, including Faculty Affairs. With this background information, it is now possible to describe the development of a performance evaluation system for such an organization.

\section{Faculty Performance Evaluation}

\section{Faculty Assessment}

During the academic year 1997-1998 as a result of various indications of faculty dissatisfaction, a Climate Study was conducted to attempt to isolate and identify root causes of the faculty concerns. _The survey yielded the following:

1. Faculty was unsure of the specific job expectations held by their respective deans.

2. Frequent and significant changes were routinely made to the faculty members' job responsibilities by the deans, without input or prior discussion with the affected faculty member.

3. Faculty members did not feel that their deans valued their performance of their jobs, especially in light of a newly instituted merit pay policy.

4. Faculty workloads, coupled with the uncertainty of their specific responsibilities, and the lack of stability in their jobs, served to create a feeling among faculty of being overworked.

5. Faculty were experiencing difficulty in preparing for promotion and tenure because of a lack of consistency in performance evaluations and the lack of definitive standards for the various aspects of their responsibilities.

Simply put, the climate was one in which faculty members did not know what their job was, the job kept changing without faculty input, the work load appeared to be overwhelming ${ }_{2}$ and faculty were not being rewarded for the work they did.

The Faculty Council (now named Faculty Senate) tasked the University Faculty Affairs Committee to develop solutions to the problems identified by the Climate Study. The Faculty Affairs Committee include: the chair who was a strong leader and very politically astute and persuasive speaker; a professor with extensive experience in performance evaluation, compensation and strategic planning; and an experienced professor of organizational behavior and development.

\section{Formulating the System}

The committee concluded that three objectives should guide the resolution of the climate problems:

1. Develop clear job expectations for the entire faculty that would assure that each member would be working to accomplish their personal goals, the goals of their department, and those of the university.

Clear job expectations would show how this integration of organizational and personal goals would be successful. More so, it would emphasize how this interactive participation would clearly benefit the university and the faculty member. Once approved by the dean, changes to these job expectations could only be made with the concurrence of the faculty member. 
2. Develop a dynamic evaluation process that involved extensive, interactive communication and negotiation between each faculty member and their respective dean.

Key elements to this objective were simplicity of documentation, clear standards of performance, and timely assessment and feedback by the dean.

3. Develop a reward and pay policy that reflected the appropriate value associated with various faculty responsibilities in order to motivate faculty members to achieve excellence in their performance and linkhow that performance to benefit for themselves and the university.

With these objectives established, the next step in formulating the concept was to create the components of an evaluation system. These components were:

1. A formal job description termed Faculty Duties and Responsibilities (FDR) guidelines consisting of four parts:

a. Instructional Performance

b. Scholarship (Teaching, Discovery, Integration, Application)

c. Professional Activities

d. University and Community Service

2. A formal Faculty Inventory document (FI), organized to reflect the performance of the various categories of the FDR.

3. A formal Dean's Performance Evaluation similarly organized but with the added requirement for documentation of accomplishments, student and peer evaluations, and other appropriate inputs.

4. Performance Standards, which guide the faculty in performing their jobs and the deans in evaluating individual faculty performance. These standards would include university criteria and department or schoolspecific criteria e.g. accreditation requirements.

5. Reward and Pay Policy consisting of four categories to demonstrate the value placed on faculty performance.
a. Cost of Living Allowance (COLA)
b. Merit Pay
c. Exceptional Performance Reward
d. Equity Adjustments

These components were developed in draft form and presented to the administration during multiple two day long working sessions. Faculty Affairs approached the development of the concept for faculty evaluation and these components from the strategic standpoint. To be effective, both faculty and administration must take ownership of the concept and each component and the best way to accomplish that was to create a partnership between faculty and administration. This partnership would also be essential in the acceptance and implementation of the concept and components to the entire faculty after formulation is completed.

\section{Building the Partnership}

The initial work session combined both strategic planning and behavioral concepts. In order to achieve agreement on the validity of the evaluation concept and content of the key components, Faculty Affairs organized the work session in such a way as to maximize participation by the key players or stake holders. To emphasize the "work session" atmosphere, the faculty members arrived at the meeting in "business casual" attire. After the first "break out session", the president, and all administrators removed their coats and ties and "became fully engaged" in the work at hand. This small act was very important in developing the spirit of cooperation and collaboration that ultimately led to successful creation of the evaluation system. 
The members of the work sessions were unique with the faculty and administration represented as follows:

\author{
Faculty \\ Affairs Committee \\ Senate
}

\author{
$\underline{\text { Administration }}$ \\ President \\ Provost \\ Vice President \\ Deans (3)*
}

*Note: During the initial formulation period there were only two deanships from the university's Humanities and Fine Arts and Professional Studies (Business Administration, Nursing, and Education). One additional dean for Extended (Evening) Studies joined later. The university was reorganized into five deanships during the implementation phase largely as a result of limitations exposed during these deliberations, which will be explained later.

\section{Creating the Components}

Job descriptions are a fundamental element in focusing faculty performance. They are also essential to tying individual achievement and personal goal accomplishment to the goals and objectives of the institution.

Unclear job expectations was the major concern of faculty in the climate study, therefore, creating the job description content was essential for creating a more favorable climate for faculty. The faculty /administration work group was presented with a draft Faculty Job Description format which had been developed by Faculty Affairs. This format was reviewed, discussed and modified by the work group and a final document was created.

| Next came the need to create a method whereby faculty could describe and communicate performance of their jobs to administration for evaluation. The Faculty Self Inventory document, also provided to the work group in draft, was similarly revised and modified by the work group, as was the Dean's Evaluation Document. Because of the two dean's prior experience and preferences, the groups agreed that for the first evaluation period, the format for the evaluations would be that used previously by the respective deans. Subsequently, a standardized Dean's Evaluation Form has been created and implemented partly as a result of the reorganization discussed previously and the in| stallation of five new deans.

A second "work session" of the same group of faculty and administration, held several weeks later, resulted in three finalized documents:

1. Faculty Job Description (Faculty Duties and Responsibilities or FDR)*

2. $\quad$ Faculty Self Inventory (FSI)**

3. Dean's Evaluation Form (individualized for the 2 deans)

FDR and FSI key elements included:

*Faculty members create their FDR and obtain dean approval

| ** FDR as Addendum to the Contract for the faculty member

The FDR can be modified as necessary to meet the needs of the faculty member or the university; however, all changes must be agreed to by both the member and Dean. A review process to resolve disputes between the member and dean was also accomplished.

Faculty members create their FSI to describe how they have performed the job during the previous contract year. FSI includes supporting documentation of performance and a section permits a narrative summary of how the faculty member feels they have contributed to the university's goals, their personal goals for the future and how they 
intend to accomplish those goals.

A series of university-wide forums were conducted resulting in minor modifications to the FDR. The concept and documents were presented to the University Board of Trustees and were accepted for implementation. Evaluation of a faculty member's performance now is a simple matter of reviewing the pre-agreed upon job description and the documentation provided by the faculty member demonstrating performance. These documents, supplemented by Dean's observations and supervision, result in a formal evaluation which is the basis for decisions regarding compensation, future contracts, developmental actions, if necessary, and rank and tenure recommendations.

To provide for possible revisions, a trial period was established prior to implementing the full system.

\section{Implementation}

The first components of the system, the FDR, FSI, were implemented for the $1999-2000$ academic year. Forums and help sessions were offered to assist faculty is preparing their FDRs as well as FSIs and individual members of Faculty Affairs served as liaison with the various departments to ease the implementation process.

\section{Continued Formulation}

Concurrently, with implementation of the FDR and FSI concepts, Faculty Affairs began to develop the remaining two components of the evaluation system: creation of a Reward and Pay Policy (to ensure that faculty performance was approximately valued) and Performance Standards to be used to assess the work reported in the FSI.

A key player in this endeavor was a new chair of Faculty Affairs - an extremely talented team builder especially adept at articulating the intricacies and benefits of the system and dealing with the political issues. There were some changes in the committee's membership; however, the chair was very successful in maintaining the initiative's focus and momentum.

Of more serious concern, which significantly complicated the implementation process was the reorganization of the university into five schools (from the previous two) and the installation of deans for these schools, none of which had been involved in the development of the new evaluation system and its components, nor had they been privy to the guidance provided by the university president during the initial "work sessions" to develop the system. The need for reorganization surfaced during the work sessions when administration became aware of the problems caused by the numbers of individual faculty being supervised by the two Deans. As will be discussed later, this reorganization and the personalities and goals of the new deans, and their experience with supervision, have had a major impact on much of the implementation and acceptance of the entire system.

The same process, as had been used to initiate the system, was employed to finalize the Reward and Pay Policy and Performance Standards components. A "work session” with Faculty Affairs, Faculty Senate and Administration was conducted and the documents were reviewed and modified.

The Reward and Pay Policy established four categories of Compensation/Reward:

1. COLA

2. Merit Pay

3. Exceptional Performance Reward

4. Equity Adjustment*

*This latter category included Gender and Pay Compression components and was specifically added at the request of the University President in a private meeting with Faculty Affairs.

Similarly, the General Guidelines of Standards of Performance was created. A major issue in standards of performance centers on the recognition that the university faculty perform a wide variety of tasks and have equally 
varied responsibilities and make varied contributions. Additionally, many of the schools (Business Administration, Nursing, and Education) have accreditation guidelines and requirements. Therefore, it became essential that the standards of performance incorporate these unique requirements and that creation of these standards was best left to the various schools. The schools' standards must then be submitted to Faculty Senate for review and assessment to | ensure compatibility with the overall university expectations and requirements.

The Chair of Faculty Affairs presented the Reward and Pay Policy and Standards of Performance to the University Board of Trustees where they were approved for implementation.

| During the presentation to the board, the University President made these points:

1. That a single person representing faculty and another representing the administration acting as a facilitators were essential in advocating the successful implementation of this faculty evaluation system.

2. That deans' would be held accountable for their successful implementation of the system and its application to faculty members.

3. That the entire faculty would be continuously evaluated under the system and appropriate developmental | actions would be used by the deans to ensure faculty excellence.

\section{Current Status}

The entire system is fully implemented and evaluations have been completed for academic years 1999_ 2000,2000-2001, and 2001-2002.,2000 and 2001. Faculty compensation for the academic year 2001-2002 reflects the job descriptions documented in the Faculty Duties and Responsibilities Document, Faculty Self-Inventories and the Deans Evaluations. Performance standards have been developed by each College and are being used by both faculty and the deans to refine job requirements and expectations.

As a direct result of the Pay and Reward Policy development, Faculty Affairs undertook a comprehensive analysis of faculty compensation, with approval for the University President, and subsequently, with the involvement of the Vice President for Academic Affairs. This analysis covered the academic years of 1999-2000 and 20002001. Significant differences in salary levels were discovered among individual faculty members. The Administration has taken action to begin to rectify the differences effective with contracts for the academic year 2001-2002 and further refinement of compensation levels will be a continuing process. That such an analysis of sensitive, compensation matters initiated by the Faculty Affairs Committee was supported by the University President and produced prompt, positive corrective action serves as an excellent example of the collaborative relationship between faculty and administration that has characterized this entire project.

\section{Problems and Issues}

| The following two problem areas have been significant during the implementation of the system:

The timeline for individual faculty to complete the job description (FDR) and the self-inventory (FSI) has not been enforced uniformly by the college Deans. For example, the FDR for the next academic year was frequently not discussed with the individual faculty member until the Fall Semester was well underway. This resulted in delaying decisions on changes in the job expectations and slowed faculty development momentum.

Faculty submits their self-inventories in May for the previous academic year. Contracts for the following academic year are issued in April, therefore, rewards contained in the contract salary, are not based on the most current performance. Instead, salaries are based on the Dean's Evaluation of the FSI from the previous year.

A second area that has caused difficulty has been the development of performance standards for the various

job duties and responsibilities in the different colleges. For example, -scholarship activities are expected to follow Boyer's definitions (Boyer, 1990). Individual deans have applied interpretations of the standards, which have caused some confusion and concern among faculty. Criteria set by some accrediting agencies further complicate the devel- 
opment and application of performance standards among the different colleges.

Efforts are on going to resolve these two problems. Individual deans and faculty in each college are studying the feasibility of adjusting the submission and review timeline for the FDR and FSI. As a part of the workload study initiative, discussed in the next section of this paper, performance standards will be further refined.

\section{Continuing Initiatives}

Workload has been, and remains, a key issue for faculty and administration. The documentation of faculty job descriptions, self-inventories and the dean's evaluations provide a substantial amount of information on what faculty members have done and are doing. Analysis of these documents by faculty groups and administration will form the basis for decisions regarding workload expectations and, ultimately, rewards that will motivate faculty to perform.

Compensation levels among ranks and disciplines remain a high priority issue. The broad adjustments made as a result of the previous analysis serve as a starting point for on-going assessment. The issue of pay compression is the next area of concern. Because of the high costs associated with alleviating inequities in this category of compensation, extensive analysis will be necessary. Continued collaborative efforts by faculty and administration will be required to successfully resolve this issue.

\section{Conclusion}

The development and implementation of a process for evaluating the performance of faculty has successfully produced a system that will, in time, correct the problems which existed in the climate at this university. By creating a collaborative working relationship between faculty and administration, it was possible to construct documents and an administrative procedure that meets everyone's needs and, ultimately, strengthens the linkage between the objectives of the individual faculty members and the goals of the university.

The collaborative model discussed here is only part of providing, sustaining, and enhancing quality in higher education. Finding and implementing credible quality measures are important to enhancing and building quality on quality. Communication is key and "the challenge of performance feedback" (Nelson \& Quick, 2000, p. 193) is a communication challenge and when met, an effective appraisal system can mature with "five key characteristics: validity, reliability, responsiveness, flexibility, and equitableness" (p. 194).

The authors wish to specifically recognize the contributions of the Chairs of the Faculty Affairs Committee, Margaret Mitchell and Christy MacKinnon, without whose leadership, this complex and innovative project could not have been successful.

\section{References}

1. America's Best Colleges, 2002 Rankings. Retrieved November 30, 2001, from http://www.usnews.com/usnews/edu/college/rankings/rankindex.htm.

2. Boyer, E. L. (1990). Scholarship reconsidered: Priorities of the professorate. Princeton, NJ: The Carnegie Foundation for the Advancement of Teaching.

3. Bright, D., \& Richards, M. (2001). The academic deanship: Individual careers and institutional roles. San Francisco: Jossey-Bass.

4. Nelson, D. L., \& Quick, J. C. (2000). Organizational behavior: Foundations, realities, \& challenges $\left(3^{\text {rd }}\right.$ ed.). Cincinnati: South-Western College. 
Notes 